\title{
Selective oxidative degradation of azo dyes by hydrogen peroxide catalysed by manganese(II) ions
}

Jevan Bennett ${ }^{\mathrm{a}}$, Yusuf A. Miah ${ }^{\mathrm{a}}$, Dhimal S. Varsani ${ }^{\mathrm{a}}$, Enrico Salvadori $^{\mathrm{b} *}$ and Tippu S. Sheriff ${ }^{\mathrm{c} *}$

${ }_{5}$ Manganese(II) ions catalyse the oxidative degradation of Calmagite (H3CAL) dye in aqueous solution at $20 \pm 1{ }^{\circ} \mathrm{C}$ in the $\mathrm{pH}$ range $7.5-9.0$ using hydrogen peroxide $(\mathrm{H} 2 \mathrm{O} 2)$ as oxidant by a mechanism that involves strong complexation to the MnII centre. It is proposed that $[\mathrm{MnIII}(\mathrm{CAL})(\mathrm{O} 2 \mathrm{H})]-$ i.e. a dye coordinated hydroperoxyl $(\mathrm{O} 2 \mathrm{H}-)$ MnIII complex is formed and bleaching of the dye is initiated by an electron-transfer to MnIII, with the binding of $\mathrm{H} 2 \mathrm{O} 2$ being the rate determining step. At $\mathrm{pH} 9.0$ in ${ }_{10}$ (bi)carbonate, HCO3-, H3CAL is rapidly bleached via the in situ formation of coordinated peroxycarbonate (HCO4-); a TOF (TOF = moles of dye bleached per mole of manganese per hour) of $\sim 5000 \mathrm{hr}-1$ can be achieved. The bleaching of the related azo dyes Orange II and Orange G is different because, unlike Calmagite, they lack an o,o-dihydroxy motif so are unable to complex strongly to MnII and no oxidation to MnIII occurs. At pH 8.0 (phosphate buffer) Orange II and Orange G are not ${ }_{15}$ bleached but bleaching can be achieved at $\mathrm{pH} 9.0$ (HCO3- buffer); the rate determining step is dye coordination and it is proposed bleaching is achieved via an outer-sphere oxygen atom transfer. Mechanisms for dye bleaching at $\mathrm{pH} 8.0$ and $\mathrm{pH} 9.0$ are proposed using data from EPR, UV/VIS and ESI-MS. MnII/ H2O2/ HCO3- form a potent oxidising mixture that is capable of removing stubborn stains such as curcumin.

20

\section{Introduction}

Higher valent manganese complexes have been implicated in a wide variety of natural, biomimetic and synthetic processes involving both substrate oxidation and reduction including photosynthetic water oxidation, dioxygen activation and reduction to hydrogen peroxide (H2O2), epoxidation and

${ }_{25}$ bleaching. The use of $\mathrm{H} 2 \mathrm{O} 2$ as the terminal oxidant in oxidation processes in favoured due to its environmentally benign nature, the byproduct in its use being water.1 From a green chemistry viewpoint it is the ideal oxidant with an atom efficiency $(47 \%)$, bettered only by dioxygen $(\mathrm{O} 2,50 \%)$, but exhibiting better reaction kinetics. Large scale uses of $\mathrm{H} 2 \mathrm{O} 2$ include the bleaching of paper in the wood pulp industry, as a detergent in the form of perborates and percarbonates in washing powders, ${ }_{30}$ and in the chemical treatment of water systems. 2

The treatment of wastewaters from dye manufacturers and the textile processing industries is a challenge 3 with azo dyes which contain the $-\mathrm{N}=\mathrm{N}-$ moiety being particularly problematic as they account for $70 \%$ of textile dyestuffs and are also chemically stable. 4 It has been estimated that 128 tonnes of dye materials are released daily into the environment and by the nature of their use they are ${ }_{35}$ designed to be resistant to environmental degradation.4, 5 Thus they are non-biodegradable under aerobic conditions and under anaerobic conditions produce hazardous intermediates. 6 The oxidative degradation of Orange II (sodium 4-[(2-hydroxy-1-naphthyl)azo]benzene sulfonate, Scheme 1), a model azo dye substrate, has been described by van Eldik and co-workers using $\mathrm{H} 2 \mathrm{O} 2$ with either MnII salts7 or MnII(bipy) 2 complexes 8 in carbonate (HCO3-) buffer in the pH range $8-10$, and MnII ${ }_{40}$ salts using commercial peracetic acid9 at $\mathrm{pH} 9.5$. 


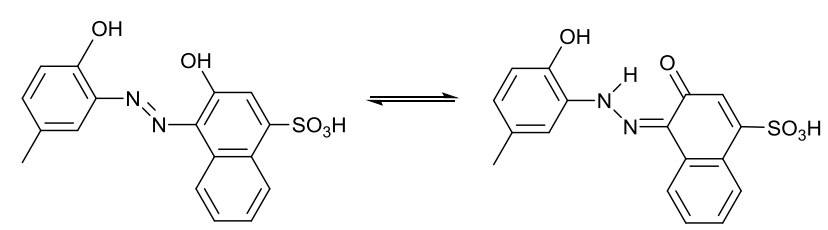

Calmagite

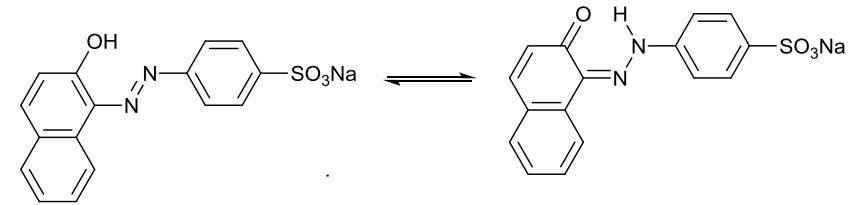

Orange II
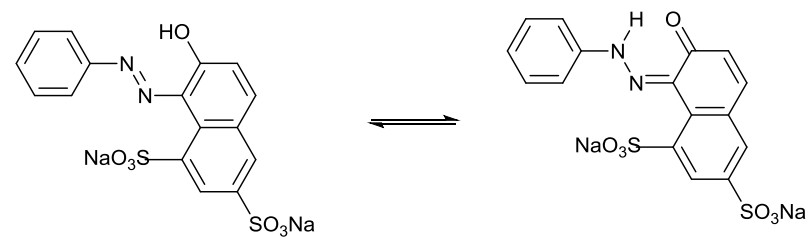

Orange $\mathrm{G}$

Scheme 1 Azo-hydrazone tautomerism of Calmagite, Orange II and Orange G in aqueous solution.

In the use of MnII salts, van Eldik found that only the HCO3- buffer system was able to oxidatively s degrade Orange II and he proposed a mechanism involving peroxycarbonate (HCO4-) that is formed when $\mathrm{H} 2 \mathrm{O} 2$ reacts with $\mathrm{HCO} 3-($ Scheme 2).

$$
\begin{aligned}
& \mathrm{H}_{2} \mathrm{CO}_{3}+\mathrm{H}_{2} \mathrm{O} \stackrel{\mathrm{pKa}_{1}=6.38}{\rightleftharpoons} \underset{\mathrm{HO}^{\prime} \mathrm{C}_{\mathrm{O}^{-}}}{\mathrm{O}}+\mathrm{H}_{3} \mathrm{O}^{+}
\end{aligned}
$$

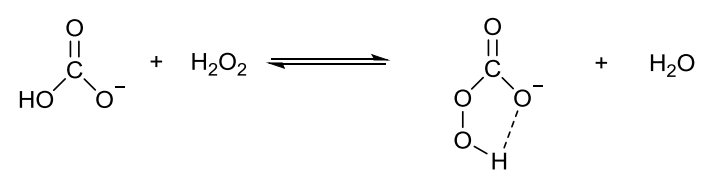

Scheme 2: Mechanism for the formation of peroxycarbonate from carbonate and hydrogen peroxide.

${ }_{10} \mathrm{HCO} 4$ - ions are reported to be several orders of magnitude more reactive than $\mathrm{H} 2 \mathrm{O} 2$ towards nucleophilic substrates 10 because carbonate $(\mathrm{CO} 32-)$ is a better leaving group than hydroxide $\quad(\mathrm{OH}-$ )11. In the presence of MnII, HCO4- is complexed to produce a MnII- $\square$ 2-peroxycarbonate complex which van Eldik proposes then breaks down to $\mathrm{MnIV}=\mathrm{O}$ that is the active catalyst in the oxidatative degradation of Orange II through the transfer of an oxygen atom. Van Eldik suggests this transfer is is assisted by the weak binding of Orange II to MnII and that this complexation stabilises the MnII- $\square 2$ peroxycarbonate pre-catalyst (Scheme 3).

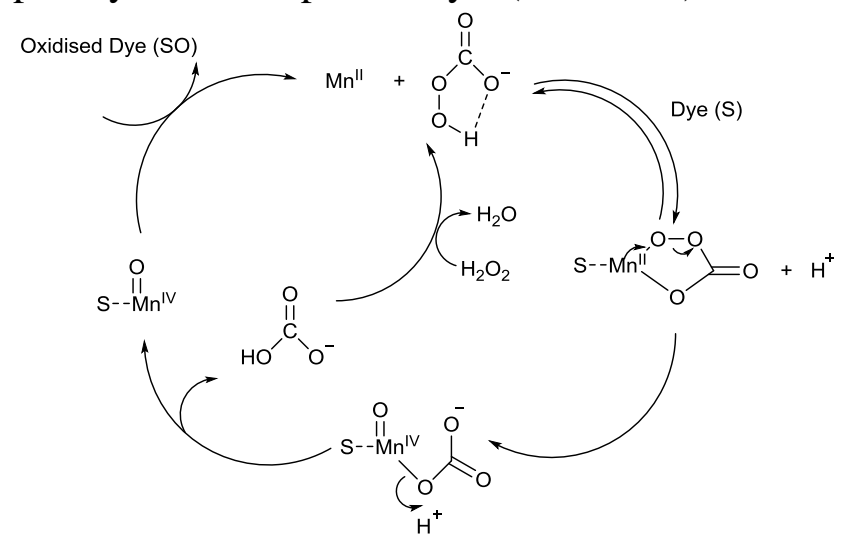


Scheme 3 Proposed mechanism for the oxidative degradation of O II via the in situ formation of MnIV=O species.

We have previously described the complete degradation of Calmagite (3-hydroxy-4-(2-hydroxy-5methylphenylazo)naphth-alene-1-sulfonic acid) under ambient conditions using in situ generated ${ }_{5} \mathrm{H} 2 \mathrm{O} 2$ catalysed by MnII ions at pH 8.0 in N-2-hydroxyethylpiperazine-N'-3-propanesulfonic acid, EPPS, buffer.12 Under these conditions Orange II and Orange G (3-hydroxy-4-

(phenylazo)naphthalene-1,5-disulfonate, disodium salt) were not bleached and it was suggested that this was because these substrates lacked an additional hydroxyl group ortho to the azo group (Scheme 1) thus resulting in weaker binding to MnII. The presence of Tiron (1,2-dihydroxybenene-3,5${ }_{10}$ disulfonate disodium salt, monohydrate, Na2TH2 $\cdot \mathrm{H} 2 \mathrm{O}$ ), with [Tiron]/[dye] $\sim 15$ was required for efficient in situ generation of $\mathrm{H} 2 \mathrm{O} 2$. The mechanism for oxidative degradation of Calmagite was proposed to involve a MnIII-OOH species within a highly oxidizing MnIII Tiron-quinone complex, with no evidence of $\mathrm{MnIV}=\mathrm{O}$ species by EPR. While the in situ generation of $\mathrm{H} 2 \mathrm{O} 2$ from $\mathrm{O} 2$ for dye bleaching is highly attractive, the presence of hydroxylamine $(\mathrm{NH} 2 \mathrm{OH})$ in stoichiometric amounts as ${ }_{15}$ the reducing substrate and Tiron as an essential co-ligand makes the application of this system unsuitable for wastewater treatment. We were therefore interested to use simple MnII salts in the presence of added $\mathrm{H} 2 \mathrm{O} 2$ to investigate the oxidative degradation of Calmagite, Orange II and Orange $\mathrm{G}$ as model substrates in the $\mathrm{pH}$ range 7.5-9.0 using both phosphate and carbonate buffer systems. These substrates were chosen because they represent a range of MnII binding abilities viz. Calmagite ${ }_{20}$ >> Orange II $\sim$ Orange G. In this study we wish to detect the differences in the mechanisms of dye bleaching at $\mathrm{pH} 8.0$ (phosphate) and $\mathrm{pH} 9.0$ (carbonate) and to determine if we could detect $\mathrm{MnIV}=\mathrm{O}$ species in the latter system by EPR, as previously reported by van Eldik.7 The use of $\mathrm{H} 2 \mathrm{O} 2$ provides a cheap and more atom economic oxidant compared to peracetic acid (and other peracids) and hypochlorite (which also releases chlorine into the environment). There are a wide range of metal ${ }_{25}$ Systems known to catalyse the degradation of azo dyes but these are associated with elaborate ligand systems which add expense and chemical demands in the treatment of wastewater. The use of simple MnII salts in these systems is viewed as benefical in terms of economics and atom efficiency, thus realising the goals of green chemistry.

\section{${ }_{30}$ Results and Discussion}

\section{Calmagite}

Fig. 1 is a visible spectrum scan (400-700 nm) showing the change in absorbance of an aqueous solution of Calmagite (H3CAL henceforth referred to as 'CAL', $0.100 \mathrm{mM}, \square \max \sim 540 \mathrm{~nm}$ ) ${ }_{35}$ at $\mathrm{pH} 8.0 \pm 0.1$ (phosphate buffer) and $20 \pm 1{ }^{\circ} \mathrm{C}$ in the presence of added $\mathrm{H} 2 \mathrm{O} 2(50.0 \mathrm{mM})$ and aqueous $\mathrm{Mn} 2+(5.00 \square \mathrm{M})$ as catalyst (initial molar ratio Mn: CAL: H2O2 = 1: 20: 10,000).

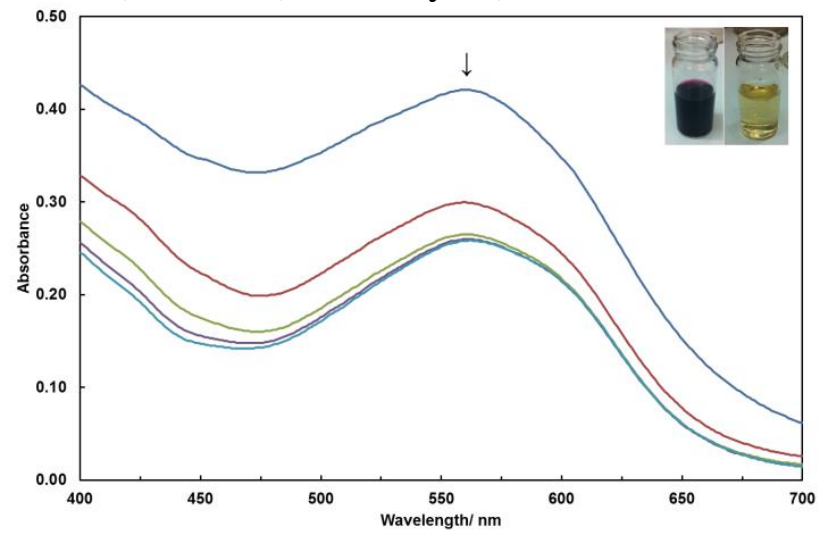


Fig. 1 The change in absorbance spectrum of CAL at $5 \mathrm{~min}$ intervals from $\mathrm{t}=0$ to $\mathrm{t}=20 \mathrm{~min}$ at $20 \pm 1^{\circ} \mathrm{C}$ with

$[\mathrm{MnCl} 2 \cdot 4 \mathrm{H} 2 \mathrm{O}]$ at $5.00 \square \mathrm{M}$. Initial [CAL] and [H2O2] were $0.100 \mathrm{mM}$ and $50.0 \mathrm{mM}$ respectively. The pH was $8.0 \pm 0.1(50$ $\mathrm{mM}$, phosphate buffer). Insert: The colour of CAL before (left) and after (right) the reaction.

${ }_{5}$ There is an initial rapid decrease in [CAL] $(\mathrm{t}=0-5 \mathrm{~min})$ followed by smaller decreases [CAL] with time. At the end of the $20 \mathrm{~min}$ period there is no trace of the purple colour in the reaction solution (Fig. 1 (insert)). Previous studies on the in situ generation of $\mathrm{H} 2 \mathrm{O} 2$ and CAL dye bleaching were carried out at $\mathrm{pH} 8.0$ using the non-coordinating, biological, EPPS buffer; the use of phosphate buffer here seems not to have any detrimental affect on the ability of the MnII to catalyse this reaction suggesting that ${ }_{10}$ phosphate can easily be displaced by CAL in coordination sites around MnII. In this coordinated state it would be expected that the azo form of CAL would dominate over the hydrazine tautomer (Scheme 1) with electron density concentrated on the oxygen atom.12 The effect of the variation of [MnII] between 0 and $100 \square \mathrm{M}$ on the oxidative degradation of CAL is shown in Fig. 2 and ESI $\uparrow$.

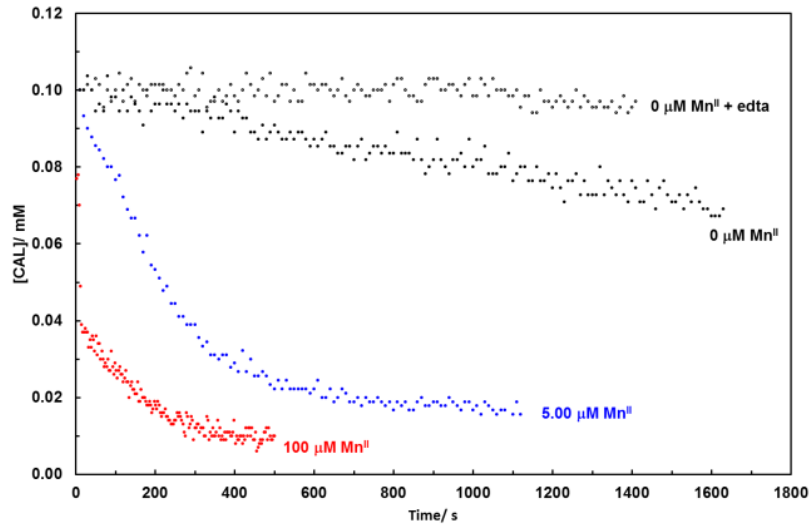

${ }_{15} \mathrm{Fig} .2$ The change in [CAL] with time monitored at $540 \mathrm{~nm}$ and at $20 \pm 1^{\circ} \mathrm{C}$ with $[\mathrm{MnCl} 2 \cdot 4 \mathrm{H} 2 \mathrm{O}]$ varied from 0 , and with added ethylenediaminetetraacetic acid (EDTA, $1.00 \mathrm{mM}$ ), to $100 \square \mathrm{M}$. Initial [CAL] and [H2O2] were $0.100 \mathrm{mM}$ and 50.0 $\mathrm{mM}$ respectively. The $\mathrm{pH}$ was $8.0 \pm 0.1$ (50 mM, phosphate buffer).

In the absence of added MnII there is only slow bleaching of CAL and this is stopped almost ${ }_{20}$ completely in the presence of ethylene diamine tetra-acetate (EDTA4-, $1.00 \mathrm{mM}$ ), and is presumably due to the presence of adventitious MnII. [MnII] as low as $0.500 \square \mathrm{M}$ catalyses the bleaching of CAL. At $5.00 \square \mathrm{M}$ and lower concentrations of MnII, the rate of bleaching is independent of the [CAL] ([CAL]/[MnII] > 20 initially) suggesting that coordination of CAL to MnII is fast. With an excess of $\mathrm{H} 2 \mathrm{O} 2$, there is a first order dependency on $[\mathrm{MnII}]$ (ESI1 $\dagger$ ) with the pseudo first order rate constant ${ }_{25}$ calculated to be $3.9 \times 10-2 \mathrm{~s}-1$ with a TOF of $\sim 140 \mathrm{hr}-1$. There are small increases in the rate of CAL bleaching when the $\mathrm{pH}$ is raised from 7.5 to 8.0 and then 8.5. This is consistent with an increase in the [HO2-] (pKa H2O2 = 11.6714) with relative [HO2-] at pH 7.5, 8.0 and 8.5 of 1: 3.3: 10 respectively and this suggests that the coordination of $\mathrm{H} 2 \mathrm{O} 2$ may be the rate determining step. Unsurprisingly, the rates of reaction and TOF observed here are much faster than that observed previously using in situ ${ }_{30}$ generated $\mathrm{H} 2 \mathrm{O} 2$ (from $\mathrm{O} 2$ ) where the equilibrium concentration of oxidant is lower and competition for binding sites around the manganese greater due to the presence of reducing substrate hydroxylamine $(\mathrm{NH} 2 \mathrm{OH}, 100 \mathrm{mM})$ and ligand Tiron $(1.50 \mathrm{mM}) .13$ A first order dependency of CAL bleaching on [H2O2] (ESI2 $\dagger$ ) and [CAL] (ESI3 $\dagger$ ) was observed but the rate of bleaching was found to be independent of the [phosphate]. To gain insight into the chemical species formed during the ${ }_{35}$ reaction cycle, we employed electron paramagnetic resonance (EPR) spectroscopy. For semi-integer spin systems, e.g. MnII $S=5 / 2$, the highest EPR sensitivity (i.e. higher transition probability) is achieved with the external field and the microwave field perpendicular to each other. For integer spin systems, e.g. MnIII $S=2$, the transition probability drops to zero when the external field and the applied magnetic field are perpendicular, but is largest when they are parallel. The EPR spectrum (X- 
band, perpendicular mode) of a solution of MnII (100 $\square \mathrm{M})$ at $\mathrm{pH} 8.0$ (phosphate buffer) containing $\mathrm{H} 2 \mathrm{O} 2(50.0 \mathrm{mM})$ revealed the characteristic six-line spectrum $(\mathrm{ESI} 4 \dagger)$ of the high-spin ion $(\mathrm{S}=5 / 2)$ coupled to the manganese nucleus $(55 \mathrm{Mn}, \mathrm{I}=5 / 2)$. When the EPR experiment was repeated in both perpendicular and parallel modes after the addition CAL $(0.100 \mathrm{mM})$, the six line spectrum ${ }_{5}$ (perpendular mode) was still present (Fig. 3) but there was no evidence for the presence of MnIII species (parallel mode) nor was there any signal at $\sim 150 \mathrm{mT}(\mathrm{g} \sim 4.5)$ in perpendicular mode indicative of $\mathrm{MnIV}=\mathrm{O}(\mathrm{S}=3 / 2)$.

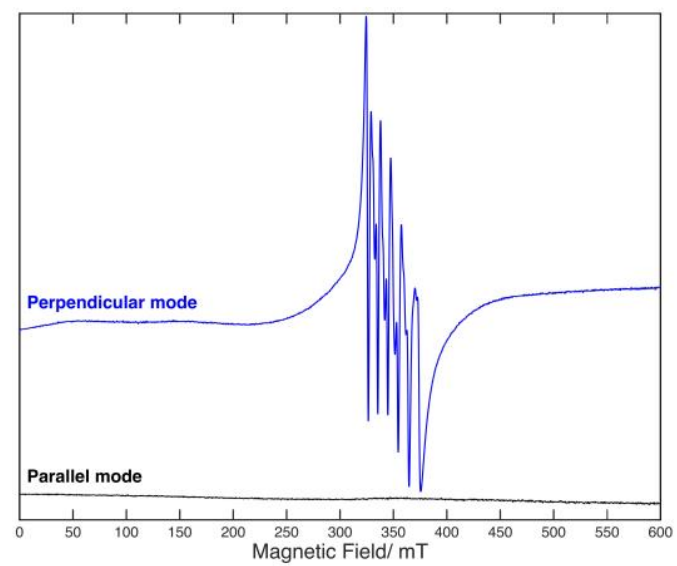

Fig. $3 \mathrm{X}$-band EPR spectra of $\mathrm{MnCl} 2 \cdot 4 \mathrm{H} 2 \mathrm{O}(100 \square \mathrm{M}), \mathrm{H} 2 \mathrm{O} 2(50.0 \mathrm{mM})$ and $\mathrm{CAL}(0.100 \mathrm{mM})$ at $\mathrm{pH} 8.0(50 \mathrm{mM}$, ${ }_{10}$ phosphate buffer) in both perpendicular $(9.65 \mathrm{GHz})$ and parallel $(9.41 \mathrm{GHz})$ modes. EPR conditions: $10 \mathrm{~K}, 2 \mathrm{~mW}$ microwave power, modulation amplitude $0.5 \mathrm{mT}$.

On the other hand, MnIII was observed in the EPR (parallel mode) when an aqueous solution of $\mathrm{MnCl} 24 \mathrm{H} 2 \mathrm{O}(0.10 \mathrm{mM})$ was added to aqueous Tiron $(\sim 0.30 \mathrm{mM})$ at $\mathrm{pH} 8.0(50 \mathrm{mM}$ EPPS $)$ to form ${ }_{15}$ [MnIII(T)2]5- in situ by aerial oxidation15 (Fig. 4). The measured signal is faint and does not display any resolved hyperfine structure, nonetheless its resonance position $(\mathrm{g} \sim 8.1)$ is consistent with previously reported MnIII signals. 16

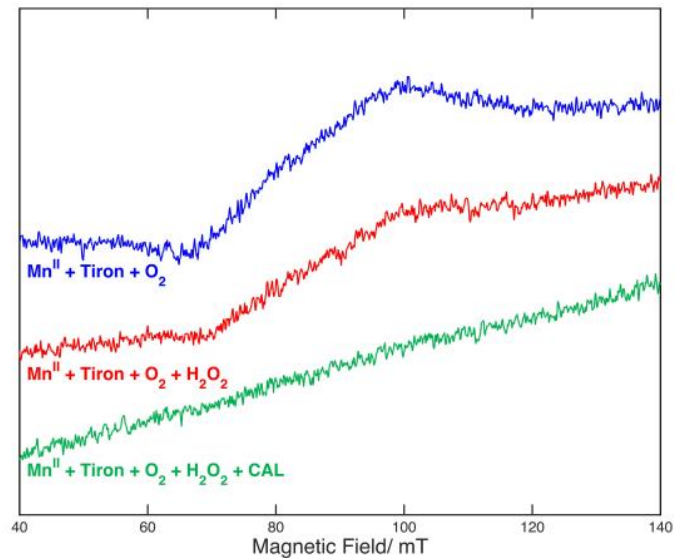

Fig. $4 \mathrm{X}$-band EPR spectra of $\mathrm{MnCl} 2 \cdot 4 \mathrm{H} 2 \mathrm{O}(100 \square \mathrm{M})$ and Tiron $(\sim 0.30 \mathrm{mM})$ at $\mathrm{pH} 8.0(50 \mathrm{mM}$, phosphate buffer) ${ }_{20}$ followed by the addition of $\mathrm{H} 2 \mathrm{O} 2(50.0 \mathrm{mM})$ and then CAL $(0.100 \mathrm{mM})$. EPR conditions: Parallel mode, $9.41 \mathrm{GHz}, 10 \mathrm{~K}$, $2 \mathrm{~mW}$ microwave power, modulation amplitude $0.5 \mathrm{mT}$.

When $\mathrm{H} 2 \mathrm{O} 2(50 \mathrm{mM})$ was added the MnIII signal was still observable, whereas when CAL (0.100 $\mathrm{mM}$ ) was introduced the signal disappeared. This suggests that in the presence of excess CAL (and $\left.{ }_{25} \mathrm{H} 2 \mathrm{O} 2\right)$ the equilibrium [MnIII] is low as it is reduced to MnII due to a one-electron transfer from bound CAL, which in turn initiates the oxidative degradation of the dye. Returning to the added $\mathrm{H} 2 \mathrm{O} 2$ 
system (without Tiron), Fig. 5 shows the results of a semi-quantitative EPR study at pH 8.0 (phosphate buffer) in which the height of the peak at lowest magnetic field $(\sim 315 \mathrm{mT})$ was used as a proxy for [MnII] present.

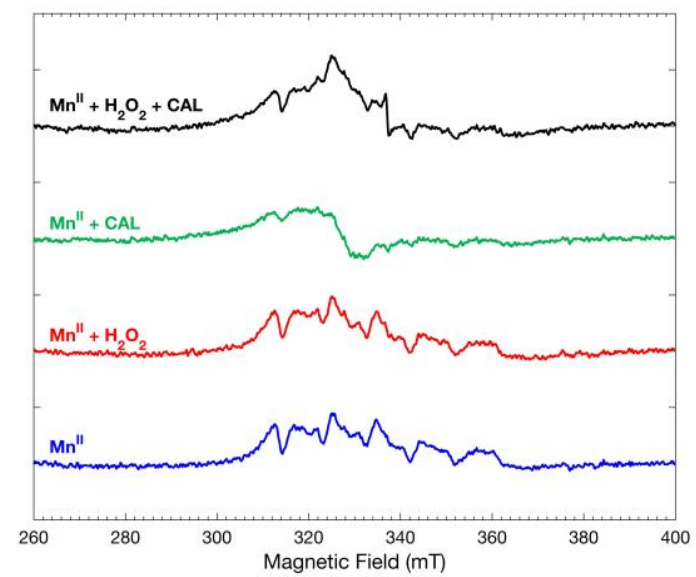

5 Fig. $5 \mathrm{X}$-band EPR spectra of $\mathrm{MnCl} 2 \cdot 4 \mathrm{H} 2 \mathrm{O}(100 \square \mathrm{M}), \mathrm{H} 2 \mathrm{O} 2(50.0 \mathrm{mM})$ and $\mathrm{CAL}(0.100 \mathrm{mM})$ at $\mathrm{pH} 8.0(50 \mathrm{mM}$, phosphate buffer) in perpendicular $(9.45 \mathrm{GHz})$ mode. EPR conditions: $10 \mathrm{~K}, 2 \mathrm{~mW}$ microwave power, modulation amplitude $0.7 \mathrm{mT}$.

When only $\mathrm{H} 2 \mathrm{O} 2$ was added there was no observable change in [MnII], indicating that this state is ${ }_{10}$ quite stable despite the presence of an excess of a strong oxidant. When the experiment was repeated with CAL but no $\mathrm{H} 2 \mathrm{O} 2$, there was a large decrease in MnII signal, possibly due to the formation of the MnIII-CAL complex. Similar to Mn/Tiron system, this d4 state is presumably stabilised by the CFSE now gained by the coordination of a relatively strong-field ligand. With both CAL and $\mathrm{H} 2 \mathrm{O} 2$ present, there is a $\sim 50 \%$ reduction in MnII signal, and the assumed $\sim 50 \% \mathrm{MnII} / \mathrm{MnIII}$ present is due to the ${ }_{15}$ presence of both reduced and oxidised Mn species as coordinated CAL is 1-e- oxidised. None of the EPR data shows any evidence of radical species and when CAL bleaching was repeated in the presence of an excess of the radical scavenger 2,4,6-tri-tert-butylphenol there was no reduction in the rate of oxidative degradation suggesting that the mechanism does not involve radical species e.g. $\bullet \mathrm{OH}$ and $\bullet \mathrm{O} 2 \mathrm{H}$. Fig. 6 shows an UV/VIS spectrum of a mixture of MnII with $\mathrm{H} 2 \mathrm{O} 2$ (pH 8.0, phosphate ${ }_{20}$ buffer) exhibiting an absorption peak at $\sim 240 \mathrm{~nm}$ due to the formation of a MnII-hydroperoxo complexref; this peak is substantially broadened and red shifted on the addition of CAL and the peak decreases only slowly over a period of $30 \mathrm{~min}$. The change in the UV part of the spectrum on addition of CAL is presumably due to the binding of CAL to the metal centre and subsequent oxidation of MnII to MnIII and the very small changes in the UV region thereafter suggests that as CAL is oxidatively ${ }_{25}$ decomposed there is fast coordination of remaining CAL to the metal centre, with rapid mineralisation of the initial oxidation products of the dye. 


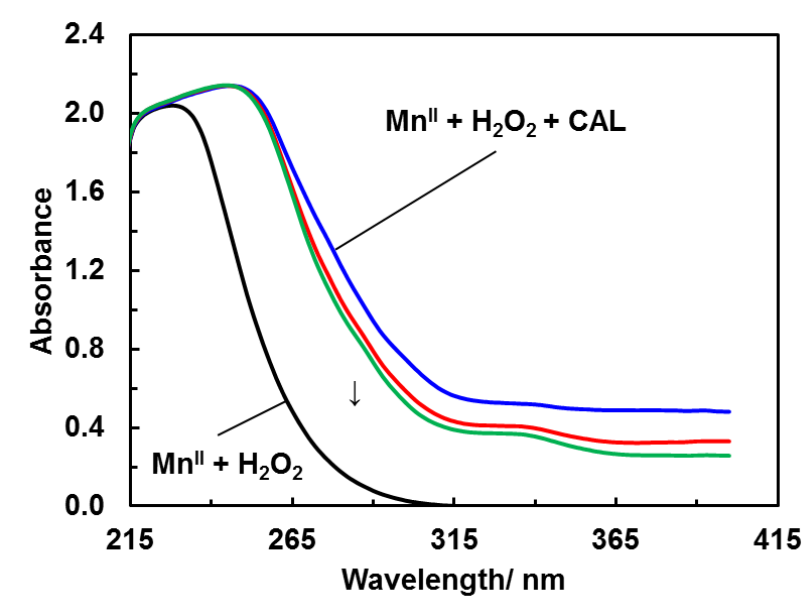

Fig. 6 UV/VIS spectrum of a CAL bleaching solution at $20 \pm 1{ }^{\circ} \mathrm{C}$ before and after the addition of CALwith then repeat scans until $\mathrm{t}=30 \mathrm{~min}$. [MnCl2 $4 \mathrm{H} 2 \mathrm{O}$ ] was $5.00 \square \mathrm{M}$ and the initial [CAL] and [H2O2] were $0.100 \mathrm{mM}$ and $50.0 \mathrm{mM}$ respectively. The $\mathrm{pH}$ was $8.0 \pm 0.1$ (50 $\mathrm{mM}$, phosphate buffer).

An ESI-MS chromatogram (ESI5 $\dagger$ ) of a CAL bleaching solution shows high intensity peaks at $\mathrm{m} / \mathrm{z}$ 450.3 and $\mathrm{m} / \mathrm{z} 484.8$ that correspond to [MnIII(NaCAL)(H2O)]+ and [MnIII(NaHCAL)(O2H)(H2O)]+ species respectively; these peaks were absent when MnII was not added. Taken together, the kinetic, UV/VIS, EPR and MS data are consistent with a mechanism for CAL bleaching that involves the ${ }_{10}$ oxidative degradation of coordinated CAL in the presence of coordinated $\mathrm{HO} 2-$ at a MnIII centre (eqn (1)-(4)).

$$
\begin{aligned}
& \mathrm{MnII}+\mathrm{H} 3 \mathrm{CAL} \text {; }[\mathrm{MnII}(\mathrm{CAL})]-+3 \mathrm{H}+\quad(1) \\
& 2[\mathrm{MnII}(\mathrm{CAL})]-+1 / 2 \mathrm{O} 2+2 \mathrm{H}+\mathbf{q} 2[\mathrm{MnIII}(\mathrm{CAL})]+\mathrm{H} 2 \mathrm{O} \\
& { }_{15}[\mathrm{MnIII}(\mathrm{CAL})]+\mathrm{H}+2 \mathrm{O} 2 \text {; }[\mathrm{MnIII}(\mathrm{CAL})(\mathrm{O} 2 \mathrm{H}]-+\mathrm{H}+ \\
& {[\mathrm{MnIII}(\mathrm{CAL})(\mathrm{O} 2 \mathrm{H}]-\rightarrow \mathrm{MnII}+\mathrm{CAL} \text { oxid. products }}
\end{aligned}
$$

Step (4) can be considered to be fast given the lack of observable MnIII in the EPR parallel mode. The role of $\mathrm{H} 2 \mathrm{O} 2$ as the terminal oxidant in this system is interesting in that it could be used simply to ${ }_{20}$ reduce MnIII back to MnII in a catalase-like process, but the system is probably more complicated with coordinated peroxide taking an active role in the initiation of CAL breakdown. The presence of excess $\mathrm{H} 2 \mathrm{O} 2$ in solution is probably responsible for further oxidation of the initial oxidation product resulting in complete the mineralisation of the dye.13 Oakes et al have also proposed that specific complexation of CAL is a requirement for its oxidative degradation when using peroxosulfate as ${ }_{25}$ terminal oxidant and suggested that this may occur via a one-electron transfer from MnIII involving an inner-sphere mechanism.17 The rate of loss of CAL is given by eqn. (5).

$-\mathrm{d}[\mathrm{CAL}] / \mathrm{dt}=\mathrm{k} 1[\mathrm{Mn}(\mathrm{CAL})(\mathrm{O} 2 \mathrm{H})] \quad(5)$

When there is an excess of $\mathrm{H} 2 \mathrm{O} 2$ in solution and the [CAL] is large, the rate of CAL bleaching can be expressed as eqn. (6).

${ }_{30}-\mathrm{d}[\mathrm{CAL}] / \mathrm{dt}=\operatorname{kobs}[\mathrm{MnII}]$

We were interested to investigate the effect of Tiron on CAL dye bleaching at $\mathrm{pH} 8.0(50 \mathrm{mM}$ EPPS) as this ligand was previously found to be essential not only for the in situ generation of $\mathrm{H} 2 \mathrm{O} 2$ but also for CAL bleaching.9 In the absence of added Na2CO3 with [Tiron4-] at $1.50 \mathrm{mM}(\mathrm{Mn}$ : Tiron4-: CAL: $\mathrm{H} 2 \mathrm{O} 2=1: 30: 2: 500$ ), there is a clear lag period during which time CAL bleaching is ${ }_{35}$ inhibited. However, this lag period is reduced when sodium carbonate was added and there were stepwise reductions as the [Na2CO3] is increased to $50.0 \mathrm{mM}$ (Fig. 7). 


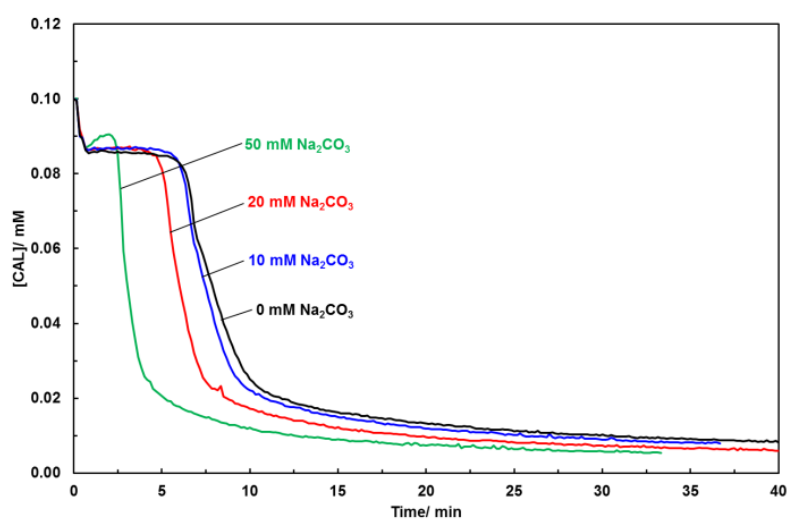

Fig. 7 The change in [CAL] with time monitored at $535 \mathrm{~nm}$ and at $20 \pm 1^{\circ} \mathrm{C}$ in the presence of Tiron with [Na2CO3] varied from 0 to $50 \mathrm{mM}$ and with [MnCl2.4H2O] at $50.0 \square \mathrm{M}$. Initial [CAL], [H2O2] and [Tiron] were $0.100 \mathrm{mM}, 50.0 \mathrm{mM}$ and $1.50 \mathrm{mM}$ respectively. The $\mathrm{pH}$ was $8.0 \pm 0.1$ (50 mM, N-2-hydroxyethylpiperazine-N'-3-propanesulfonic acid, EPPS, 5 buffer).

In the absence of added $\mathrm{Na} 2 \mathrm{CO} 3$ these results are consistent with the need for CAL to be bound to MnII for bleaching to occur and that Tiron4- can initially compete effectively for binding sites around the metal. When $\mathrm{Na} 2 \mathrm{CO} 3$ was added the in situ formation of peroxycarbonate (HCO4-) is itself able ${ }_{10}$ to compete with Tiron for binding sites around MnII ([HCO4-]/[Tiron] 6.7-33) and this leads to a progressive reduction in the lag period as the [HCO4-] is increased.

Fig. 8 shows a comparison of the rates of CAL bleaching at $\mathrm{pH} 8.0 \pm 0.1$ (50 $\mathrm{mM}$ phosphate) and at $\mathrm{pH} 9.0 \pm 0.1(50 \mathrm{mM}$ carbonate, $\square \max \sim 608 \mathrm{~nm})$ with $[\mathrm{MnII}]$ at $0.500 \square \mathrm{M}$.

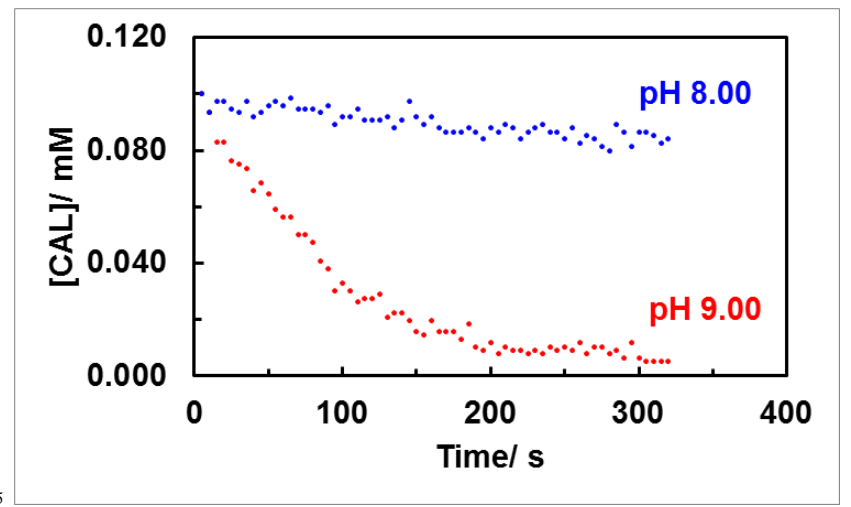

Fig. 8 The change in [CAL] with time monitored at $535 \mathrm{~nm}$ at $\mathrm{pH} 8.0 \pm 0.1(50 \mathrm{mM}$, phosphate buffer) and $608 \mathrm{~nm}(50 \mathrm{mM}$, carbonate buffer) at $20 \pm 1^{\circ} \mathrm{C}$ with [MnCl2.4H2O] at $0.500 \square \mathrm{M}$. Initial [CAL] and [H2O2] were $0.100 \mathrm{mM}$ and $50.0 \mathrm{mM}$ respectively.

${ }_{20}$ The TOF at $\mathrm{pH} 9.0$ is calculated to be $\sim 5000 \mathrm{hr}-1$ which is $\sim 35$ times larger than at $\mathrm{pH} 8.0$. These higher bleaching rates cannot be solely accounted for by the higher [HO2-] at this $\mathrm{pH}(\sim 10$ times higher than at $\mathrm{pH} 8.0$ ) and it would appear that the binding of $\mathrm{HO} 2-$ at $\mathrm{pH} 9.0$ is much faster than the binding of $\mathrm{H} 2 \mathrm{O} 2$ in phosphate buffer at $\mathrm{pH} 8.0$ and this leads to the faster formation of $[\mathrm{MnIII}(\mathrm{CAL})(\mathrm{O} 2 \mathrm{H}]-$ and can account for the faster bleaching rate under these conditions (Scheme 4). 


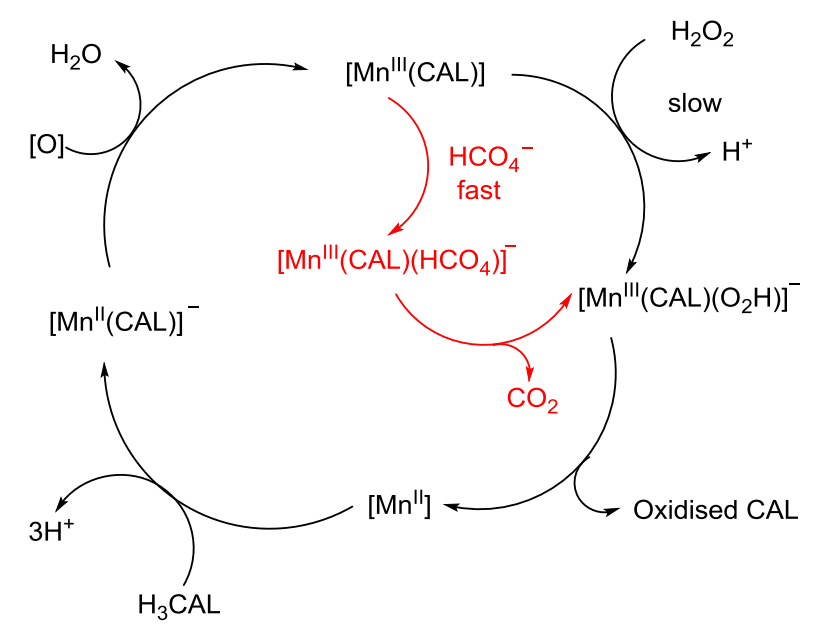

Scheme 4 Proposed mechanism for the oxidative degradation of CAL at pH 8.0 (phosphate, black) and pH 9.0 (carbonate, red).

${ }_{5}$ The reaction at $\mathrm{pH} 9.0$ was much more sensitive to adventitious MnII with slow bleaching in the absence of added MnII; this activity was again effectively reduced to zero in the presence of EDTA4$(1.00 \mathrm{mM})$. Thus while carbonate/peroxide mixtures resulting in the in situ formation of HCO4- may be viewed as strongly oxidising, accelerated rates under ambient conditions may only be observed in the presence of metal ions.

${ }_{10} \quad$ The addition of Tiron to CAL bleaching at pH 9.0 (EPPS buffer) with varying [Na2CO3] is shown in Fig. 9.

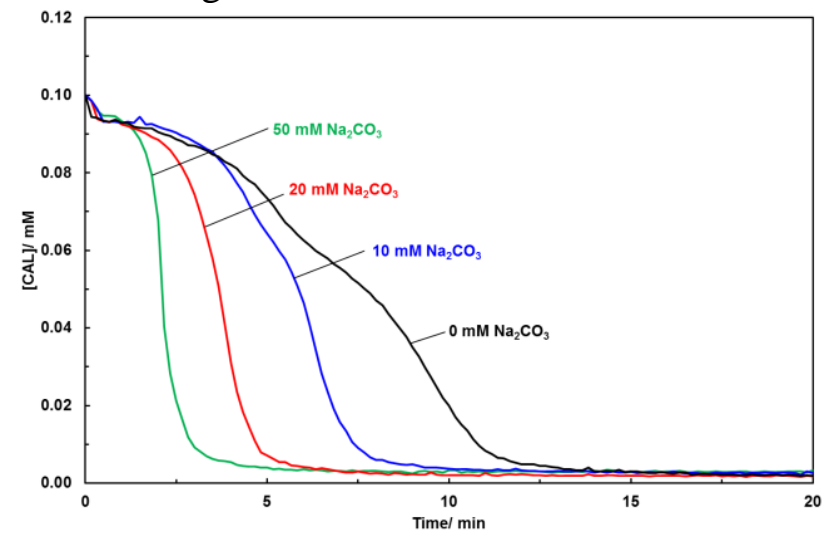

Fig. 9 The change in [CAL] with time monitored at $608 \mathrm{~nm}$ and at $20 \pm 1^{\circ} \mathrm{C}$ in the presence of Tiron with [Na2CO3] varied from 0 to $50 \mathrm{mM}$ and with [MnCl2 $4 \mathrm{H} 2 \mathrm{O}$ ] at $50.0 \square \mathrm{M}$. Initial [CAL], [H2O2] and [Tiron] were $0.100 \mathrm{mM}, 50.0 \mathrm{mM}$ and

${ }_{15} 1.50 \mathrm{mM}$ respectively. The $\mathrm{pH}$ was $9.0 \pm 0.1(50 \mathrm{mM}, \mathrm{N}-2$-hydroxyethylpiperazine-N'-3-propanesulfonic acid, EPPS, buffer).

In general the lag periods were found to be smaller than at $\mathrm{pH} 8.0$ and the rates of dye bleaching faster with saturation at $\sim 50 \mathrm{mM} \mathrm{Na} 2 \mathrm{CO} 3$ consistent with the maximum stoichiometric amount of HCO4${ }_{20}$ that can be formed in solution at $\mathrm{pH} 9.0$ (Scheme 2).

\section{Orange II and Orange G}

Fig. 10 and Fig. 11 show repeat UV/VIS scans $(300-700 \mathrm{~nm})$ of aqueous solutions of Orange II (O II, $\left.{ }_{25} 0.100 \mathrm{mM}, \square \max \sim 484 \mathrm{~nm}\right)$ and Orange $\mathrm{G}(\mathrm{O} G, 0.100 \mathrm{mM}, \square \max 486 \mathrm{~nm}$ ) respectively at $\mathrm{pH}$ $9.0 \pm 0.1$ (carbonate buffer) and at $20 \pm 1^{\circ} \mathrm{C}$ in the presence of added $\mathrm{H} 2 \mathrm{O} 2(50.0 \mathrm{mM})$ and aqueous $\mathrm{Mn} 2+(5.00 \square \mathrm{M})$ as catalyst. 


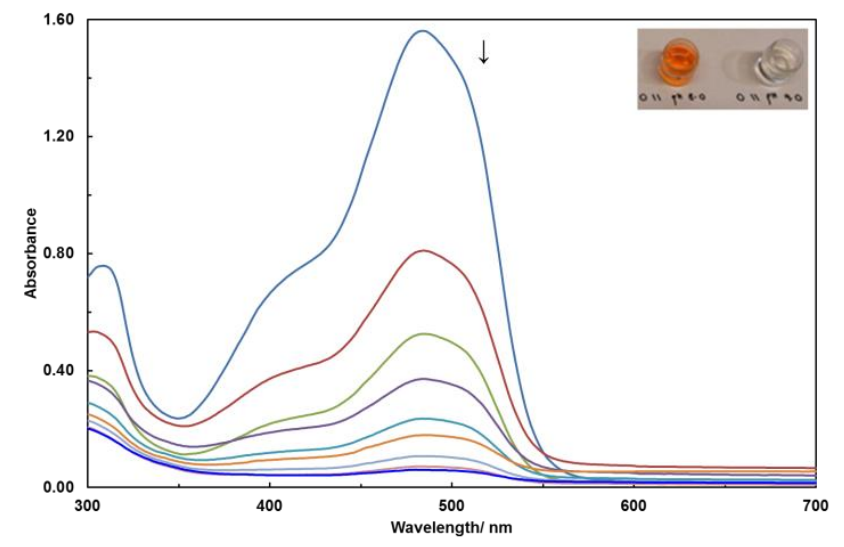

Fig. 10 The change in $[\mathrm{O} \mathrm{II}]$ from $\mathrm{t}=0$ to $\mathrm{t}=10 \mathrm{~min}$ and then at $5 \mathrm{~min}$ intervals to $45 \mathrm{~min}$ monitored at $484 \mathrm{~nm}$ and at $20 \pm 1{ }^{\circ} \mathrm{C}$ with [MnCl2 $\left.4 \mathrm{H} 2 \mathrm{O}\right]$ at $5.00 \square \mathrm{M}$. Initial [O II] and [H2O2] were $0.100 \mathrm{mM}$ and $50.0 \mathrm{mM}$ respectively. The $\mathrm{pH}$ was $9.0 \pm 0.1(50 \mathrm{mM}$, carbonate buffer). Insert: The colour of O II after attempted oxidative degradation at $\mathrm{pH} 8.0$ (left, no ${ }_{5}$ change) and at $\mathrm{pH} 9.0$ (right, completely bleached).

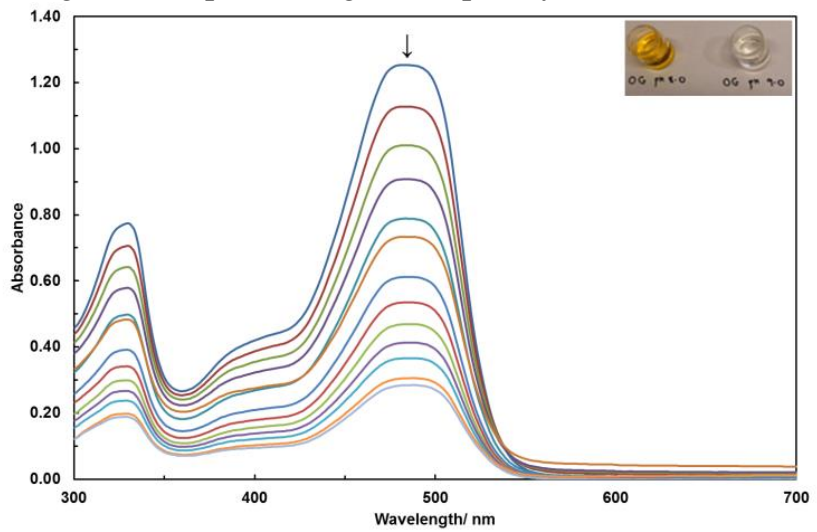

Fig. 11 The change in $[\mathrm{O} G]$ from $\mathrm{t}=0$ to $\mathrm{t}=60 \mathrm{~min}$ at $5 \mathrm{~min}$ intervals to $45 \mathrm{~min}$ monitored at $486 \mathrm{~nm}$ and at $20 \pm 1^{\circ} \mathrm{C}$ with [MnCl2 $4 \mathrm{H} 2 \mathrm{O}]$ at $\quad 5.00 \square \mathrm{M}$. Initial [O G] and [H2O2] were $0.100 \mathrm{mM}$ and $50.0 \mathrm{mM}$ respectively. The pH was $9.0 \pm 0.1$ ( $50 \mathrm{mM}$, carbonate buffer). Insert: The colour of $\mathrm{O} \mathrm{G}$ after attempted oxidative degradation at $\mathrm{pH} 8.0$ (left, no change) and 10 at $\mathrm{pH} 9.0$ (right, completely bleached).

For these dyes not only is there a decrease in the absorbance of the broad colour chromophore centered at $\sim 484 \mathrm{~nm}$ (and shoulder at $\sim 500 \mathrm{~nm}$ in the case of O II) but also a decrease in the absorbance of the naphthalene ring absorbance at $\sim 320 \mathrm{~nm}$, suggesting complete mineralisation of the dyes. These ${ }_{15}$ results are different to that obtained by Nunes et al using manganese(II) hydroxybenzyl-pyridyldiamine complexes in the oxidative degradation of methyl orange where there was an increase in the absorbance at $\sim 330 \mathrm{~nm}$ attributed to the formation of the amine oxide. 18 When the bleaching of O II and $\mathrm{O} G$ was attempted at $\mathrm{pH} 8.0$ (phosphate or EPPS, Fig. 10 and Fig. 11, inserts), there was no change in the colour of the dyes over a period of $\sim 30 \mathrm{~min}$. Van Eldik also reported that O II was not ${ }_{20}$ bleached in any other of a range of buffer systems (including phosphate) in the pH range 8-9.7 Fig. 12 and Fig. 13 show the effect of the variation of [MnII] between 0 and $100 \square \mathrm{M}$ on the bleaching of O II and $\mathrm{O} G$ respectively. 


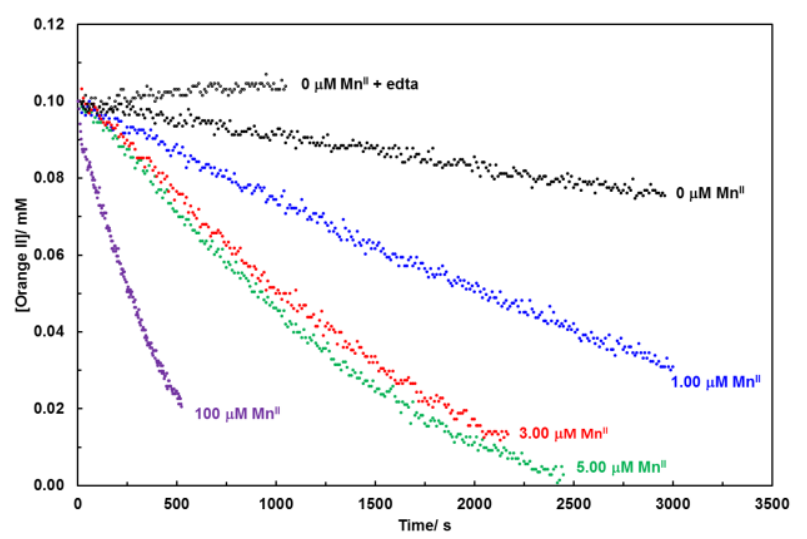

Fig. 12 The change in [O II] with time monitored at $484 \mathrm{~nm}$ and at $20 \pm 1^{\circ} \mathrm{C}$ with [ $\mathrm{MnCl} 2.4 \mathrm{H} 2 \mathrm{O}$ varied from 0 to $100 \square \mathrm{M}$. Initial [O II] and [H2O2] were $0.100 \mathrm{mM}$ and $50.0 \mathrm{mM}$ respectively. The $\mathrm{pH}$ was $9.0 \pm 0.1$ (50 mM, carbonate buffer).

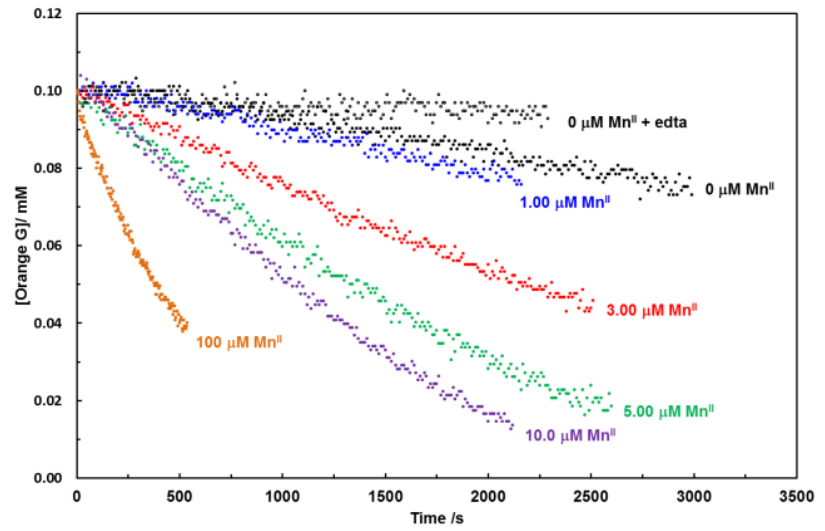

5 Fig. 13 The change in $[\mathrm{O} \mathrm{G}]$ with time monitored at $486 \mathrm{~nm}$ and at $20 \pm 1^{\circ} \mathrm{C}$ with [MnCl2.4H2O varied from 0 to $100 \square \mathrm{M}$. Initial [O II] and [H2O2] were $0.100 \mathrm{mM}$ and $50.0 \mathrm{mM}$ respectively. The $\mathrm{pH}$ was $9.0 \pm 0.1$ (50 mM, carbonate buffer).

In the absence of added MnII there is slow adventitious MnII bleaching of the dyes and this is virtually stopped in the presence of EDTA4- $(1.00 \mathrm{mM})$. [MnII] as low as $1.00 \square \mathrm{M}$ catalyses the bleaching of ${ }_{10}$ the dyes and there is an unexpected $\sim 1 / 2$ order dependency on [MnII] (ESI6 $\dagger$ ) for both dyes with pseudo first order rate constants for $\mathrm{O}$ II and $\mathrm{O} G$ calculated to be $1.4 \times 10-2 \mathrm{~s}-1$ and $6.2 \times$ $10-3 \mathrm{~s}-1$ respectively giving TOFs of $\sim 50 \mathrm{hr}-1$ and $\sim 20 \mathrm{hr}-1$ respectively. These TOFs is $\sim 100$ times lower than that for CAL bleaching at $\mathrm{pH} 9.0$ using carbonate buffer and this reflects the lower binding constants of O II and O G to MnII compared to CAL. Again, rather unexpectedly there are ${ }_{15}$ similar fractional order dependencies on [H2O2] (ESI7 $\dagger$ ) and HCO3- (ESI8 $\dagger$ ) of $\sim 1 / 2$ and $\sim 3 / 4$ for both dyes. These fractional order dependencies suggest that the catalytic system is complicated and merit further investigation. A UV/VIS spectrum of solution an $\mathrm{O} G$ bleaching solution is shown in Fig. 14. Before the addition of $\mathrm{O} G$ there is a peak centered at $\sim 245 \mathrm{~nm}$ presumably due to the MnII- $\square 2$ peroxycarbonate complex. This peak is broadened and red shifted on the addition of $\mathrm{O} G$ and there is ${ }_{20}$ then a decrease in the absorption of this peak over a period of $60 \mathrm{~min}$. At the end of $60 \mathrm{~min}$ (when all the $\mathrm{O} G$ would be exhausted), the UV/VIS spectrum is almost identical to the spectrum containing $\mathrm{MnII}$ and $\mathrm{H} 2 \mathrm{O} 2$ only indicating that the change in spectrum is reversible and is due to the weak binding of $\mathrm{O} G$ to the metal centre. A very similar spectrum was obtained with $\mathrm{O}$ II. These changes are presumably due to the formation and subsequent decomposition of a manganese-peroxycarbonate ${ }_{25}$ Species. 


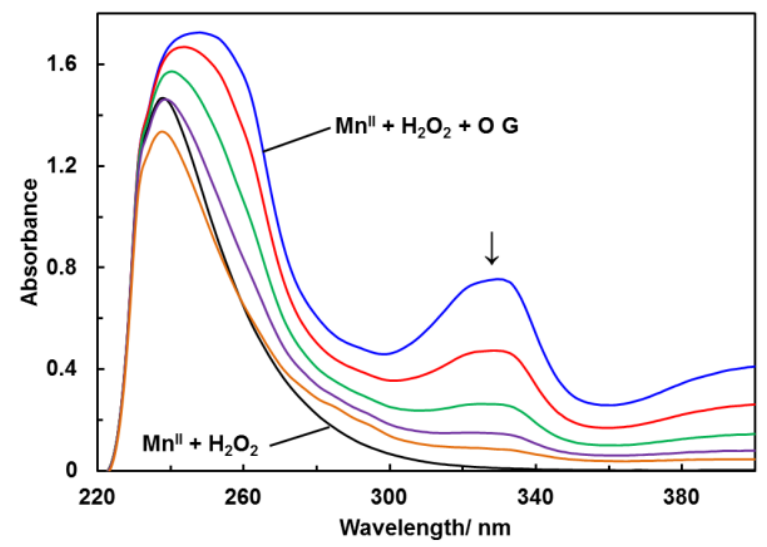

Fig. $14 \mathrm{UV} /$ VIS spectrum of a $\mathrm{O} \mathrm{G}$ bleaching solution at $20 \pm 1^{\circ} \mathrm{C}$ before and after the addition of $\mathrm{O} \mathrm{G}$ with then repeat scans until $\mathrm{t}=60 \mathrm{~min}$. [ $\mathrm{MnCl} 2 \cdot 4 \mathrm{H} 2 \mathrm{O}$ ] was $5.00 \square \mathrm{M}$ and the initial [O G] and [H2O2] were $0.100 \mathrm{mM}$ and $50.0 \mathrm{mM}$ respectively. The $\mathrm{pH}$ was $9.0 \pm 0.1$ (50 $\mathrm{mM}$, carbonate buffer).

The EPR spectrum of a solution of MnII $(100 \square \mathrm{M})$ at pH 9.0 (HCO3- buffer) exhibits the usual sixline pattern, which appears to be broadened and exhibit distinctive anisotropy as compared to its counterpart in phosphate buffer, presumably because of the coordination of the HCO3- anion (ESI $4 \dagger$ ). On addition of $\mathrm{H} 2 \mathrm{O} 2 \quad(50.0 \mathrm{mM})$ the six-lines pattern sharpens up but reduces, however there is no ${ }_{10}$ evidence for a signal at $\mathrm{g} \sim 4.5(\sim 150 \mathrm{mT})$ characteristic of $\mathrm{MnIV}=\mathrm{O}$. This six line spectrum is again prominent on the addition O II $(0.100 \mathrm{mM})$, yet there is no evidence for the formation of MnIV=O species at $150 \mathrm{mT}(\mathrm{g} \sim 4.5)$ in perpendicular mode nor MnIII in parallel mode at $100 \mathrm{mT}$ (ESI9 $\uparrow$ ), nor any decrease in the $[\mathrm{MnII}]$ in a bleaching solution containing $\mathrm{O}$ II, as judged from the height of the peak at lowest magnetic field at $\sim 315 \mathrm{mT}$ (ESI10 $\dagger$ ). These results are at odds with the mechanism ${ }_{15}$ proposed by van Eldik who implicated $\mathrm{MnIV}=\mathrm{O}$ species for $\mathrm{O}$ II bleaching in carbonate buffer at $\mathrm{pH}$ 8.5.7 However, van Eldik did not carry out any EPR studies in his work and so the involvement of $\mathrm{MnIV}=\mathrm{O}$ in these systems is somewhat speculative. A similar set of EPR spectra were obtained when $\mathrm{O}$ II was replaced by O G. This work suggests that $\mathrm{MnIV}=\mathrm{O}$ is either not formed or is a very transient species in this system. When $\mathrm{O}$ II and $\mathrm{O}$ G bleaching were repeated in the presence of an excess of ${ }_{20}$ 2,4,6-tri-tert-butylphenol there was no reduction in the rate of dye bleaching. This implies that the mechanism does not involve radical species. The rate determining step in the oxidative degradation of $\mathrm{O}$ II and O G is the coordination of the dye substrate to MnII. Analogous to Scheme 4 for CAL in the presence of carbonate, a mechanism can be proposed for the bleaching of O II and OG that in the last step involves an oxygen atom transfer to dye substrate (S) from coordinated HO2- (Scheme 5).

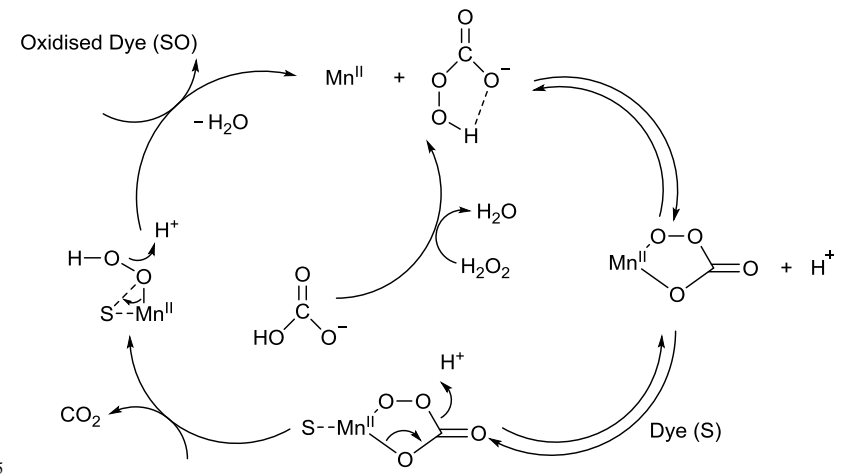

Scheme 5 Proposed mechanism for the oxidative degradation of O II and O G via the in situ formation of MnII-O-O-H species.

The final step in the oxidation of dye substrate is similar to the mechanism proposed by van Eldik but ${ }_{30}$ in this outer coordination sphere process there is no requirement for the formation of $\mathrm{MnIV}=\mathrm{O}$ species. 
The fractional order dependencies on $\mathrm{MnII}, \mathrm{H} 2 \mathrm{O} 2$ and $\mathrm{HCO} 3-$ may be explained by the complex series of equilibria in the formation of $\mathrm{HCO} 4-$ and its consumption in the release of $\mathrm{CO} 2$ and in the formation of MnII-OOH. This mechanism does require a change in oxidation state of MnII and fits the EPR data obtained. Manganese is effectively acting as a binding centre enabling transfer of an oxygen s atom from bound oxidising agent to bound dye substrate. The differences in the rate of dye bleaching and TOF values between CAL, O II and $\mathrm{O} \mathrm{G}$ at pH 9.0 (carbonate buffer) may be explained by the differences in their complexation to the manganese centre in the stabilisation of the in situ formed dyemanganese-peroxybarbonate species. The better a dye is able to bind to MnII and stabilise this species (with oxidation to MnIII with CAL) the greater the rate of oxidative degradation (Table 1).

Table 1 Summary of the rate constants (k) and turnover frequencies (TOF) at $20 \pm 1^{\circ} \mathrm{C}$ for the manganese(II) catalysed oxidative degradation of dyes using hydrogen peroxide. In all cases the initial [Dye] was $0.100 \mathrm{mM}$, [buffer] was 50 $\mathrm{mM}$, [H2O2] was $50.0 \mathrm{mM}$ and $[\mathrm{MnCl} 2 \cdot 4 \mathrm{H} 2 \mathrm{O}]$ was $5.00 \square \mathrm{M}$.

\begin{tabular}{|c|c|c|c|}
\hline Fig. & Dye & $\mathrm{pH} /$ buffer & $\begin{array}{l}\mathrm{k} / \mathrm{s}-1(\mathrm{TOF} / \\
\mathrm{hr}-1) 1\end{array}$ \\
\hline 1/ESI1 & Calmagite & $\begin{array}{l}8.0 / \\
\text { phosphate }\end{array}$ & $\begin{array}{l}3.9 \times 10-2 \\
(140)\end{array}$ \\
\hline 8 & Calmagite & $\begin{array}{l}9.0 / \\
\text { carbonate }\end{array}$ & $\begin{array}{l}1.4 \times 100 \\
(5000)\end{array}$ \\
\hline 12/ESI6 & Orange II & $\begin{array}{l}9.0 / \\
\text { carbonate }\end{array}$ & $\begin{array}{l}1.4 \times 10-2 \\
(50)\end{array}$ \\
\hline 13/ESI6 & Orange $\mathrm{G}$ & $\begin{array}{l}9.0 / \\
\text { carbonate }\end{array}$ & $\begin{array}{l}6.2 \times 10-3 \\
(20)\end{array}$ \\
\hline
\end{tabular}

${ }_{15} 1 \mathrm{TOF}=$ turnover frequency $=$ moles of dye oxidised per mole of $\mathrm{MnCl} 2 \cdot 4 \mathrm{H} 2 \mathrm{O}$ per hour.

We have determined the stability constants for the complexation of MnII with O II and O G based on the reduction in the wavelength maxima for 5.00 $\times 10-5 \mathrm{M}$ concentrations of the dyes on the addition of $1.00-6.00 \times 10-5 \mathrm{M}$ concentrations of $\mathrm{MnCl} 2 \cdot 4 \mathrm{H} 2 \mathrm{O}$ (ESI1 $\dagger$ ). The log stability constants for O II ${ }_{20}$ and $\mathrm{O} \mathrm{G}$ were calculated to be identical at 4.31 which is very close to a previously reported value 4.57 for O II. The log stability constant for the coordination of MnII to CAL has a value of 11.519.

Therefore the binding constant of CAL for MnII is 107 greater than that for O II and O G and this can account for its ability to be rapidly bleached by an inner-sphere electron transfer from MnIII.

With $\mathrm{O}$ II and $\mathrm{O}$ G their weak binding ability to MnII means that MnIII is most likely not formed they ${ }_{25}$ cannot be bleached at $\mathrm{pH} 8.0$ (phosphate buffer); at pH 9.0 (carbonate buffer) oxidative degradation occurs through a more difficult outer-sphere oxygen atom transfer. The lower bleaching rates observed with $\mathrm{O}$ G compared to $\mathrm{O}$ II could be due to the presence of two sulfonate groups in its structure that reduce is binding ability still further by reducing the electron density at the phenolic oxygen anion and possibly the lone pairs of electrons on the two nitrogen atoms.

30

\section{Conclusions}

This study has shown that a simple MnII salt is able to efficiently activate $\mathrm{H} 2 \mathrm{O} 2$ and $\mathrm{H} 2 \mathrm{O} 2 / \mathrm{HCO} 3-$ mixtures to oxidatively degrade model dyes under ambient conditions. Dyes which strongly complex with the metal e.g. CAL may be degraded by a one-electron oxidation reactions at both $\mathrm{pH} 8.0$

${ }_{35}$ (phosphate) and $\mathrm{pH} 9.0$ (carbonate). O II and O G are not bleached at pH 8.0 (phosphate) but can be degraded at $\mathrm{pH} 9.0$ (carbonate) through the in situ formation of [S---MnII(OOCO2)] and oxidation occurs through an oxygen atom to the dye substrate from $[\mathrm{S}--\mathrm{MnII}(\mathrm{OOH})]$. The differences in the rates of bleaching between CAL ( $\mathrm{pH} 8.0$, phosphate) and $\mathrm{O}$ II (and $\mathrm{O} \mathrm{G}, \mathrm{pH} 9.0$ carbonate) can be compared (ESI12 $\dagger$ ) through successive additions of fresh portions of CAL and O II 
to the reaction solutions which also show only small reductions in the rates of dye bleaching at each step, suggesting that the integrity of the catalyst is preserved during these repeated cycles. Work in these laboratories has shown that even difficult to remove stains such curcumin (curry stain) may be degraded using $\mathrm{H} 2 \mathrm{O} 2 / \mathrm{HCO} 3-$ mixtures at $\mathrm{pH} 9.0$ which provide a potent oxiding medium in the presence of added MnII. The tailoring of dye bleaching to the nature of the oxidising reagent has important implications in laundry formulations in the need to remove stain molecules while not bleaching fabric dyes. One application of these findings is the development of simple colour tests for the selective detection of $\mathrm{H} 2 \mathrm{O} 2$ vapours e.g. in peroxide-based explosives. 20 Experimental Section

${ }_{10}$ Manganese(II) chloride tetrahydrate (AnalaR, 99.5\%, BDH), Tiron (1,2-dihydroxybenzene-3,5disulfonate, disodium salt, monohydrate, Sigma-Aldrich), Calmagite, Orange G (Sigma-Aldrich), Orange II (Fluka), hydrogen peroxide (30\% w/w, Sigma-Aldrich), N-2-hydroxyethylpiperazine-N'-3propane-sulfonic acid (EPPS, Sigma-Aldrich), sodium hydrogen carbonate (AnalaR, Sigma-Aldrich), potassium dihydrogen phosphate (AnalaR, BDH), sodium hydroxide pellets (semiconductor grade, ${ }_{15} 99 \%$, Sigma-Aldrich) and 2,4,6-tri-tert-butylphenol (Sigma-Aldrich) were used as received. Deionised water (ELGA Purelab) was used in all experiments and plastic spatuale were used to transfer solid reagents. (Bi)carbonate solutions were made up in boiled water (to remove dissolved CO2).21

Catalytic oxidations of the dyes were carried out at $\mathrm{pH} 7.5-9.0$ and $20 \pm 1^{\circ} \mathrm{C}$ in the presence of an excess of $\mathrm{H} 2 \mathrm{O} 2$ over dye ( 500) so that rates were not influenced by changes in [H2O2]. In ${ }_{20}$ experiments used for subsequent kinetic analysis the dye:Mn ratio was high $(>20)$ in order that absorbance readings reflected the concentration of uncomplexed dye thus simplyfing the analysis. A $500 \mathrm{~mL}$ four-necked Pyrex container was used that was specially designed to be narrow in the section containing the reaction solution so as to prevent excessive frothing of the dyes. The reaction solution was circulated using a sipper pump (JENWAY) via silicone rubber tubing through a $1 \mathrm{~mm}$ glass flow ${ }_{25}$ cell housed in a JENWAY 6315 (scanning) UV/VIS spectrophotometer and then back to the reaction vessel. The flow was at a rate such that there was no significant temperature loss between the reaction vessel and the flow cell. The remaining neck on the reaction vessel was left open for the addition of aqueous manganese(II) catalyst; this also ensured that there was no build up of pressure inside the container. In a typical experiment, potassium dihydrogen phosphate $(1.00 \mathrm{M}$, adjusted to $\mathrm{pH} 8.0 \mathrm{using}$ $\left.{ }_{30} \mathrm{NaOH}(\mathrm{aq}), 5.00 \mathrm{~mL}\right)$, aqueous Calmagite $(1.00 \mathrm{mM}, 5.00 \mathrm{~mL})$ and hydrogen peroxide $(0.500 \mathrm{M}, 5.00$ $\mathrm{mL}$ ) were added to deionised water $\sim 30 \mathrm{~mL}$ ). The $\mathrm{pH}$ of the solution was adjusted to $8.0 \pm 0.1 \mathrm{using}$ freshly prepared (CO2-free) semi-conductor grade $\mathrm{NaOH}(\mathrm{aq})$ and the solution made up to exactly 50.0 $\mathrm{mL}$. The now dark purple reaction solution was transferred to the reaction vessel and the stirrer and pump turned on. $\mathrm{MnCl} 2 \cdot 4 \mathrm{H} 2 \mathrm{O}(5.00 \mathrm{mM}, 0.500 \mathrm{~mL})$ was added and readings were commenced. The ${ }_{35}$ changes in absorbance of the solution at $540 \mathrm{~nm}(\square=10,500 \mathrm{~L} \mathrm{~mol}-1 \mathrm{~cm}-1)$ were recorded electronically at 10 second intervals. Dilute aqueous $\mathrm{HCl}$ was used to adjust the $\mathrm{pH}$ of carbonate buffer solutions to $\mathrm{pH} 9.0$.

ESI-MS chromatograms of the bleaching solutions were run on an Agilent 1100 Series LC/MSD Trap.

${ }_{40}$ The EPR experiments in figure 3 and 4 were carried out using a Bruker EMX spectrometer at X-band $(\sim 9.5 \mathrm{GHz})$, equipped with a Bruker ER 4116DM dual mode resonator $(9.41 \mathrm{GHz}$ parallel mode, 9.65 $\mathrm{GHz}$ perpendicular mode) and with an Oxford Instruments ESR900 cryostat for measurements at cryogenic temperatures $4-10 \mathrm{~K}$.

The EPR measurements in figure 5 were performed using an X/Q-band Bruker Elexsys E580 ${ }_{45}$ Spectrometer (Bruker BioSpin GmbH, Germany) equipped with a closed-cycle cryostat (Cryogenic Ltd, UK) and an X-band split-ring resonator module with $2 \mathrm{~mm}$ sample access (ER 4118X-MS2). Baseline spectra samples containing only buffer were used for baseline correction; all the spectra presented have been baseline-subtracted. 
EPR samples, 100 or $10 \mu \mathrm{L}$, contained $100 \mathrm{mM}$ aqueous $\mathrm{MnCl} 2 \cdot 4 \mathrm{H} 2 \mathrm{O}$ mixed with aqueous buffer (either phosphate or carbonate), $\mathrm{H} 2 \mathrm{O} 2$ and dye substrate and were flash-frozen and stored in liquid nitrogen $(77 \mathrm{~K})$ prior to EPR investigation. The lag time between mixing and freezing was 20 seconds. Experimental conditions are reported in the figures captions.

\section{Acknowledgement}

The authors would like to thank the EPSRC for the use of their National EPR Facility - University of Manchester and Dr Alistair Fielding for coordinating the use of the facility, Dr Ian A Sanders at the ${ }_{10}$ Analytical Services laboratory, The Joseph Priestley Building, Queen Mary University of London for ESI-MS experiments and Ms Rownok Jahan for running UV spectra as part of a 3rd year BSc project.

\section{Notes and references}

${ }_{15} 1$ G. Strukul, Catalytic Oxidations With Hydrogen Peroxide As Oxidant; Kluwer Academic Publishers, 1993. R. Hage, J. E. Iburg, J. Kerschner, J. H. Koek, E. L. M. Lempers, R. J. Martens, U. S. Racherla, S. W. Russell, T. Swarthoff, M. R. P. Vanvliet, J. B. Warnaar, L. Vanderwolf and B. Krijnen, Nature 1994, 369, 637. R. Noyori, M. Aoki and K. Sato, Chem Commun., 2003, 1977. D. Chandra and A. Bhaumik, Ind. Eng. Chem. Res., 2006, 45, 4879.

${ }_{20} 2$ J. M. Campos-Martin, G. Blanco-Brieva and J. L. Fierro, Angew. Chem. Int. Ed., 2006, 45, 6962.

3 Pollution, Prevention and Abatement Handbook, World Bank Group, Washington D.C., 1998, ISBN 0-8213-3638-X.

$4 \quad$ H. Zollinger, Color Chemistry: Synthesis, Properties and Applications of Organic Dyes and ${ }_{25}$ Pigments, Wiley, Weinheim, 3rd edn., 2003.

5 E. S. Beach, R. T. Malecky, R. R. Gil, C. P. Horwitz and T. J. Collins, Catal. Sci. Technol., $2011,1,437$.

6 G.L. Baughman and E. J. Weber, Environ. Sci. Technol., 1994, 28, 267.

7 E. Ember, S. Rothbart, R. Puchta and R. van Eldik, New J. Chem., 2009, 33, 34.

${ }_{30} 8$ S. Rothbart, E. Ember and R. van Eldik, Dalton Trans., 2010, 39, 3264.

9 S. Rothbart, E. Ember and R. van Eldik, New J. Chem., 2012, 36, 732.

10 D. Swern, Organic Peroxides, Wiley, New York, 1970, pp. 313.

11 V. Nadtochenko and J. Kiwi, J. Chem. Soc., Faraday Trans., 1997, 93, 2373.

12 J. Griffiths, J. Soc. Dyers Colour., 1971, 801; 1972, 106.

${ }_{35} 13$ T. S. Sheriff, S. Cope and M. Ekwegh, Dalton Trans., 2007, 5119. T. S. Sheriff, S. Cope and D.S. Varsani, Dalton Trans., 2013, 42, 5673.

14 M. G. Evan and N. Uri, Trans. Faraday Soc., 1949, 45, 224.

15 T.S. Sheriff, J. Chem. Soc., Dalton Trans., 1992, 1051.

16 K.A. Campbell, M.R. Lashley, J.K. Wyatt, M.H. Nantz and R.D. Britt, J. Am. Chem. Soc., ${ }_{40} 2001,123,5710$.

17 J. Oakes, P. Gratton and I. Weil, J. Chem. Soc., Dalton Trans., 1997, 3805.

18 C. A. Wegermann, P. Strapasson, S. M. M. Romanowski, A. Bortoluzzi, R. R. Ribeiro, F. S. Nunes and S. M. Drechsel, App. Cat A: Gen., 2013, 454, 11.

19 O. Abollino, C. Sarzanini and E. Mentasti, Talanta, 1994, 41, 1107.

${ }_{45} 20$ T.S. Sheriff, S. Miah and K. L. Kuok, RSC Adv., 2014, 4, 35116.

21 G.E. Delroy and E.J. King, Biochem., 1945, 39, 245.

${ }^{a} U G$ 4th year chemistry MSci project students, Department of Chemistry and Biochemistry, Queen Mary University of London, London E1 4NS, UK. ${ }^{b}$ EPR Research Facility Fellow, School of 
Biological and Chemical Science, Queen Mary University of London, Mile End Road, E1 4NS London, UK and London Centre for Nanotechnology, UCL, 17-19 Gordon Street, WC1H 0AH London, UK. E-mail: e.salvadori@qmul.ac.uk, 'Inorganic Research Laboratories, The Joseph Priestley Building, Department of Chemistry and Biochemistry, Queen Mary University of London, London E1 ${ }_{5}$ 4NS, UK. Tel: 0207882 8466; Fax: 0207882 3239. E-mail: t.s.sheriff@qmul.ac.uk

$\dagger$ Electronic Supplementary Information (ESI) available:

ESI1 Log-log plot of initial rate of CAL bleaching vs [MnII];

ESI2 Log-log plot of initial rate of CAL bleaching vs [H2O2];

${ }_{10}$ ESI3 Log-log plot of initial rate of CAL bleaching vs [CAL];

ESI4 X-band EPR spectra of $\mathrm{MnCl} 2 \cdot 4 \mathrm{H} 2 \mathrm{O}(100 \square \mathrm{M})$ at $\mathrm{pH} 8.0$ or $\mathrm{pH} 9.0$ and after the addition of $\mathrm{H} 2 \mathrm{O} 2$.

ESI5 ESI-MS chromatograms of CAL at $\mathrm{pH} 8.0$ (phosphate buffer) and CAL at $\mathrm{pH} 8.0$ (phosphate buffer) with added $\mathrm{MnCl} 2 \cdot 4 \mathrm{H} 2 \mathrm{O}$;

${ }_{15}$ ESI6 Log-log plot of initial rate of O II and O G bleaching vs [MnII];

ESI7 Log-log plot of initial rate of O II and O G bleaching vs [H2O2];

ESI8 Log-log plot of initial rate of $\mathrm{O}$ II and $\mathrm{O}$ G bleaching vs [HCO3-];

ESI9 X-band EPR spectra of $\mathrm{MnCl} 2 \cdot 4 \mathrm{H} 2 \mathrm{O}(100 \square \mathrm{M}), \mathrm{H} 2 \mathrm{O} 2(50.0 \mathrm{mM})$ and O II $(0.100 \mathrm{mM})$ at pH 9.0 (50 mM, carbonate buffer).

${ }_{20}$ ESI10 X-band EPR spectra of $\mathrm{MnCl} 2 \cdot 4 \mathrm{H} 2 \mathrm{O}(100 \square \mathrm{M})$ and with $\mathrm{H} 2 \mathrm{O} 2(50.0 \mathrm{mM})$ or O II $(0.100 \mathrm{mM})$ or both $\mathrm{H} 2 \mathrm{O} 2(50.0 \mathrm{mM})$ and $\mathrm{O}$ II $(0.100 \mathrm{mM})$ at $\mathrm{pH} 9.0(50 \mathrm{mM}$, carbonate buffer $)$.

ESI11 Change in absorbance maxima of $\mathrm{O}$ II and $\mathrm{O} \mathrm{G}$ on addition of $\mathrm{MnCl} 2 \cdot 4 \mathrm{H} 2 \mathrm{O}$;

ESI12 The change in absorbance of CAL at pH 8.0 (phosphate buffer) and O II at pH 9.0 (carbonate buffer) with time after successive additions of dye with added $\mathrm{MnCl} \cdot 4 \mathrm{H} 2 \mathrm{O}]$. 